\title{
Uninterrupted Supply to BLDC Motor using PV and Grid
}

\author{
D. Sattianadan, Hemrajsinh Parmar, Tushar Bhatt, Vineet Kumar,George Fernandez.S
}

\begin{abstract}
This paper deals with the implementation of providing an uninterrupted supply of bldc motor using PV array and utility grid. Here we have proposed a system where Brushless dc motor (used for water pumping) is driven constantly using solar photovoltaic $(P V)$ and the power grid. The solar panels providing energy is used as the main power source, thus helping reduce the load over the power grid. The grid is used as secondary or backup source to run the motor in case solar panel fails to provide sufficienct energy. The proposed system helps to supply continuous amount of power to the motor which can be used for irrigation. The energy from the solar panel is used to store energy in the battery which in turn is used to run the motor.A simulation of the proposed system is carried out to demonstrate the applicability of the system.
\end{abstract}

Keywords: Photovoltaic panel, DC-DC converter, Simulink, Voltage source inverter, PMDC motor

\section{INTRODUCTION}

As the world evolves, we are getting surrounded by numerous new electrical and electronic gadgets, which requires a high amount of power and increases overall load on the power grid. The majority of power in India is generated by non-renewable energy resources, which has increased level of pollution exponentially[1]. This calls for reducing our usage of such resources and switch to renewable energy sources.[2] Solar backed power system finds its best the power grid.

India's $70 \%$ population resides in rural areas. And the majority of them are involved in the agriculture sector. The only major requirement in farming is the constant supply of electricity for irrigation purposes. But some villages either get a limited amount of constant electricity or are isolated from the main power grid. The solar backed power system finds its best use in this type of scenario. In our proposed system we have used the solar panel as our primary source and added a lead-acid battery to store the energy from the panel. A DC-DC boost converter[3-5] is used to level up the voltage of PV panel and charge the battery. We have used power grid[6,7]as a backup supply. A VSI[10] is used to run the BLDC motor. Thus providing a continuous supply for irrigation purposes. Using BLDC motor [11-12] for irrigation

Revised Version Manuscript Received on 10, September 2019.

D. Sattianadan, SRM Institute of Science and Technology, Kattankulathur, Chennai, Tamil Nadu, India.

HemrajsinhParmar, SRM Institute of Science and Technology, Kattankulathur, Chennai, Tamil Nadu, India.

Tushar Bhatt, SRM Institute of Science and Technology, Kattankulathur, Chennai, Tamil Nadu, India.

Vineet Kumar, SRM Institute of Science and Technology, Kattankulathur, Chennai, Tamil Nadu, India.

George Fernandez.S, ,SRM Institute of Science and Technology, Kattankulathur, Chennai, Tamil Nadu, India. uses in rural areas since some of these areas are isolated from

[13] and water pumping proposes is more reliable and economically efficient as compared to other motors.

\section{Solar Cell}

A sunlight based photovoltaic or sun powered cell is a gadget that utilizes the photoelectric impact to changes over light into electric flow. It is made of silicon molecules. As the structure of silicon cell varies, we can utilize its basic property to generate electricity.

At the point when a photon with enough energy to break the bond of silicon molecules fall over it, it liberates the electrons as the bonds between them is broken and it leaves their position and now is charged to move and can consume the available space. These free electrons are called free carriers, which can move freely around the crystalline cross section. On adding impurities, for example, phosphorous, boron molecules, it takes the very least amount of energy to knock out one free electron.in this way we can have a lot of free carriers as compared to pure silicon.

To make a solar cell we have two types of silicon layer. One which is highly doped with phosphorous (N type) and the other is boron(P type). When these layers come in contact with each other they form a junction. Now no electron can cross this junction on its own. When a photon strikes the cell the energy of photon is transferred to the atom, which is sufficient enough to knock of one electron from $P$ layer pass through the barrier and reach $\mathrm{N}$ layer. Now this electron can flow around the circuit by attaching a metallic wire to both the layers. This is the way how a solar cell works.

\section{Advantages of solar cell}

- No noise pollution.

- No need for Operational maintenance.

- Does not contains any moving parts.

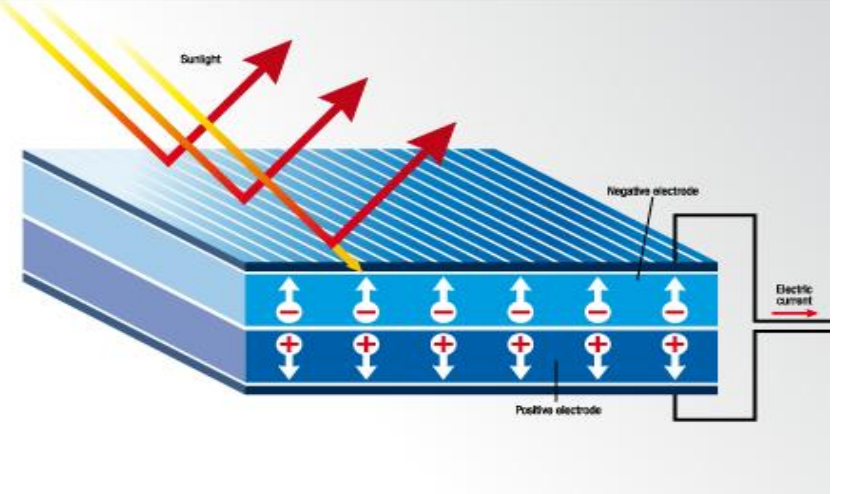

Fig.1 Solar Cell

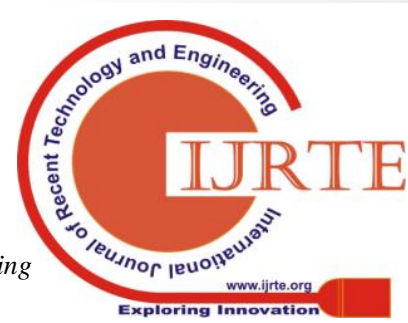




\section{Solar Panel}

A solar module consists of various solar cells electrically connected in series to achieve more voltage or in parallel to get maximum current. A solar panel is a combination of various solar modules.

A box is fitted behind the panel to get the output from the panel. It is provided protection against the rough weather conditions such as rain, dust, sandstorm etc. The conductive wires which carry the current out from the panel to the circuit may have highly conductive metals eg. Silver, copper.

Some solar panel set ups have large mirrors/reflectors to divert the sun rays directly to the panels resulting in a efficient operation of extracring the solar power.

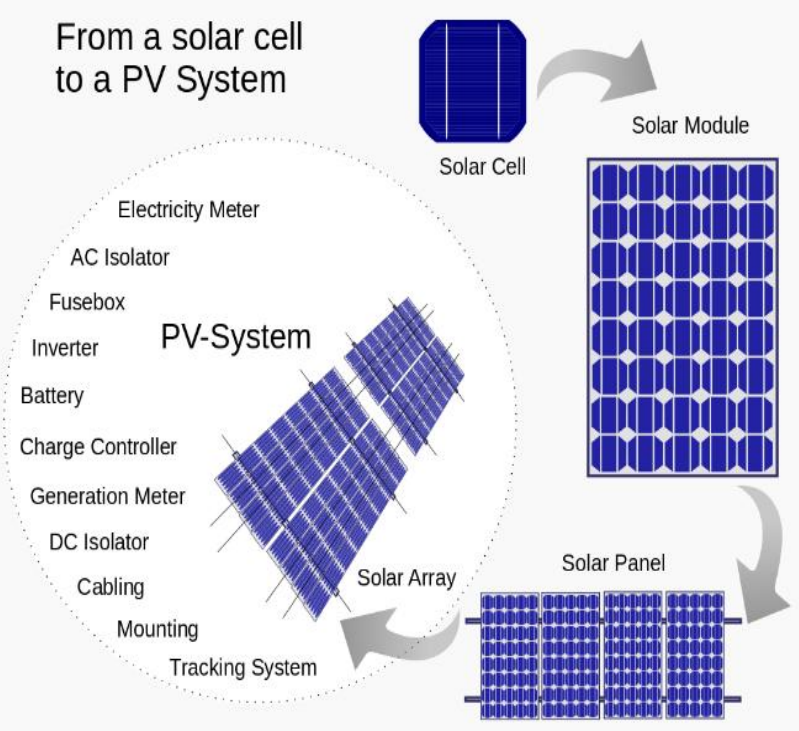

Fig.2 Solar cell to Solar Array

\section{Boost-Converter}

A boost converter comes in handy when the required voltage at the load end is not possible to get from the input source. It consist of an inductor, capacitor, switch and a diode. At first when the switch $\mathrm{S}$ as shown in the fig. 2.1 is closed, the inductor stores the current by forming a magnetic field. Now when the switch is opened the charge collapes from the inductor quickely giving rise to voltage $(\Delta \mathrm{V})$ and in addition to that the input voltage also addes up at the capacitor end, hence the resultant voltage is $(\Delta V+V)$. This is how the input voltage is steped up.

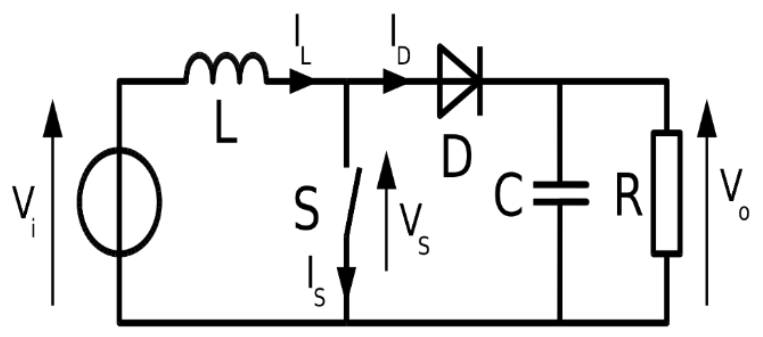

Fig.3 Boost Power Stage

\section{Brushless DC Motor}

As usual motors, brushless DC motor also has a rotor and stator. Rotor of the motor is in the form of a permanent magnet, whereas the stator is similar to that of polyphase stator winding. As the name suggests brushless, no brushes are utilized and the commutation is done electrically, it is achieved by taking feedback of stator windings.

The standards for the working of a BLDC motor that it takes the position input of the interior shaft which is equivalent to that of the brushed DC motor. In the event of a brushed DC motor, mechanical commutator and brushes are utilized to get the position. Though in BLDC motor, it is accomplished by utilizing different input sensors. By and large, the Hall impact sensor is utilized to get the situation of the rotor posts. At whatever point rotor attractive posts go close to the hall effect sensor, they create a HIGH or LOW-level flag, through which the situation of the rotor shaft can be resolved. On the off chance that the bearing of the attractive field is turned around, the voltage created will invert as well.

\section{Advantages of BLDC Motor}

- High Efficiency

- Does not cause any noise while running

- No fritional loss

- Can vary speed up to considerable range

\section{Voltage Source Inverter}

The inverter is a device that converts a direct current (DC) into alternating current (AC). As the name suggests VSI converts a DC voltage into an $\mathrm{AC}$ voltage by keeping the voltage constant. It consist of one DC source, for switching we use a transistor, diodes connected to anti parallel with a transistor and a large capacitor. For our project we have used 3-phase VSI. We have used MOSFET for switching purposes.

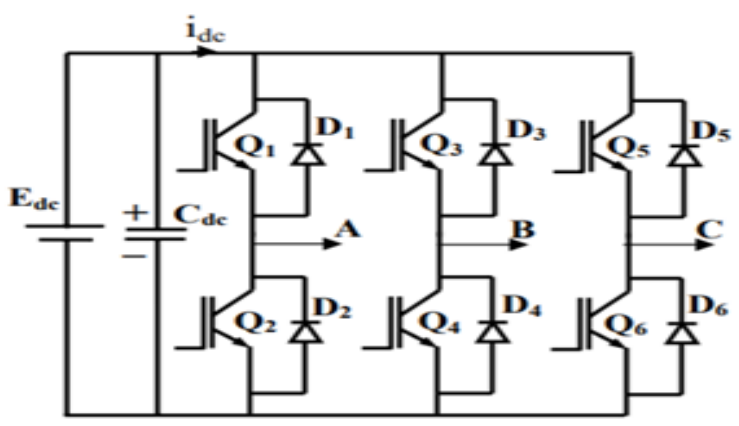

Fig.4 VSI

\section{PIC CONTROLLER}

PIC (Peripheral Interface Controller) has a place with the group of microcontrollers made by Microchip innovation. Prior PIC microcontrollers used to have ROM (Read Only Memory) or field programmable EEPROM for program storage. The ongoing models have streak memory for program storage likewise the program memory and information memory are isolated from one another. There are distinctive guidance sets for various models. PIC gadgets are extremely mainstream among businesses and research, researchers because of their minimal effort, wide accessibility, sequential programming. 
For our proposed model we have utilized PIC 16F877A PORT A, PORT B, PORT C, PORT D and It has 2 Pins TX and $\mathrm{RX}$ for sequential correspondence. $\mathrm{RX}$ is for accepting information and TX is for transmitting information. It underpins SPI convention also. 8 sticks in Port An are simple and Port B likewise has 8 sticks yet these 8 pins are computerized pins. Port $\mathrm{C}$ is additionally an advanced port same as that of Port B. Sticks in Port C pins are utilized for sequential correspondence. Port D has 8 pins which are generally computerized pins. Port E comprises just of 3 pins.

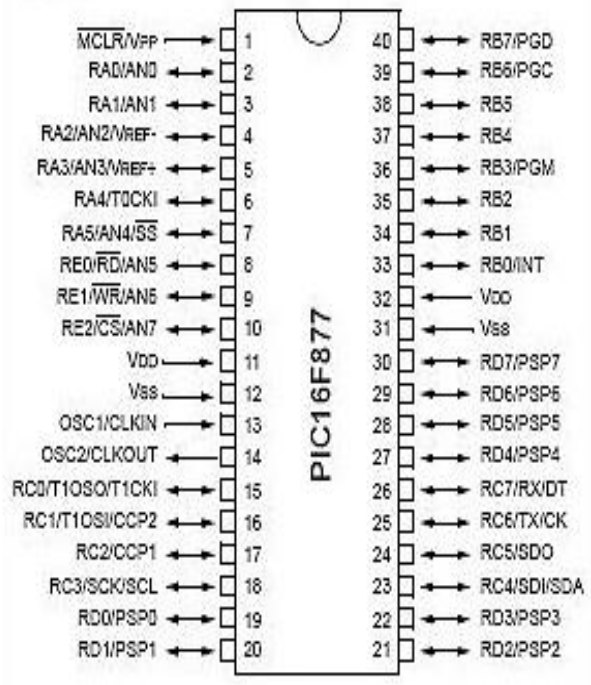

Fig.5 PIC16F877

\section{Bridge Rectifier}

A device that can give DC output voltage by using AC voltage is termed as a rectifier. Bridge rectifier consist of four diodes connected in series in such a way that only two diodes conduct for half AC cycle and the other two for the other half cycle. a capacitor is required to reduce the amount of ripple in the output waveform. The ratio of output DC power to AC input power is defined as rectifier's efficiency.

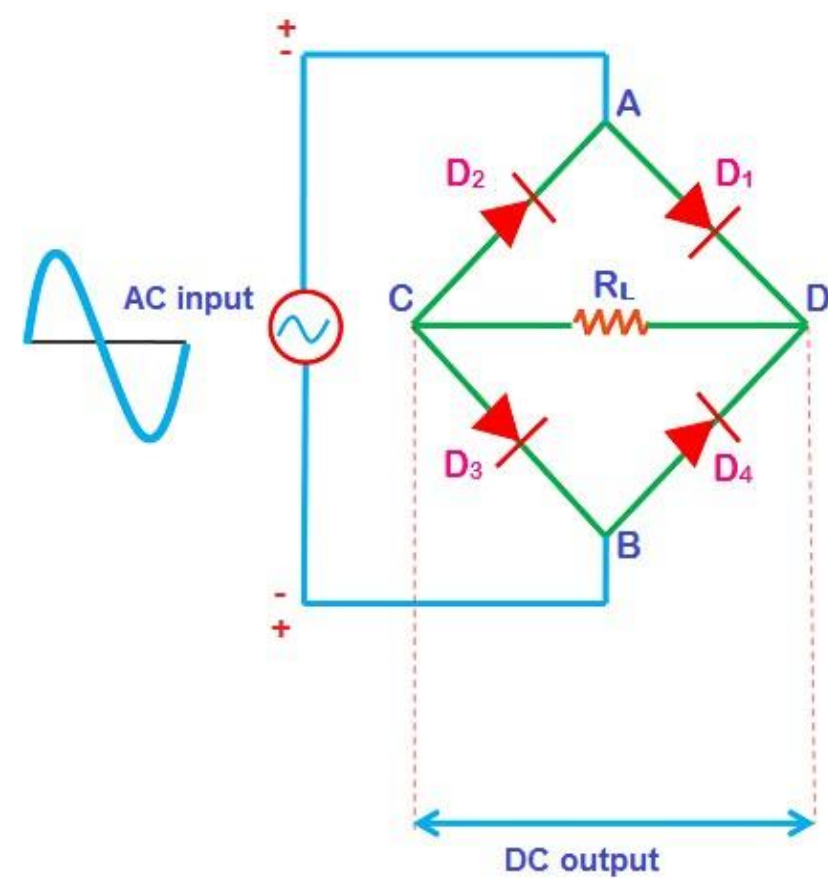

Fig.6 Bridge Rectifier

Battery

A battery is a gadget that is comprised of at least two or more than two electrochemical cells which are associated in series or parallel with one another. This could be to give power to electrical appliances, for example, Laptops, TV remotes, and e-bikes. It has two terminals positive and negative commonly known as cathode and anode respectively. It is commonly used to store the energy so that we can use it later when required. This is the reason we have taken a battery so as to store the energy generated by panel and can use dit to run motor when required.

\section{II.CIRCUIT EXPLANATION}

As shown in the above fig. the main source as PV panel of $12 \mathrm{~V}, 5 \mathrm{~W}$ is taken to charge the battery of $12 \mathrm{~V}, 1.2 \mathrm{Ah}$. To boost the voltage, as the output voltage of the PV panel is low a boost converter is used. To reach the output voltage of $12 \mathrm{~V}$ $50 \%$ of the duty cycle is used so as to keep the battery charging. Now the voltage is given to VSI to govern the BLDC motor as per the requirement. The duty cycle of the VSI inverter is controlled using a PIC Microcontroller. Since the maximum output signal voltage generated by PIC microcontroller is $5 \mathrm{~V}$ and the voltage required to trigger the MOSFET is $12 \mathrm{~V}$ we need a Gate driver circuit through which we can boost output signal voltage of PIC microcontroller. To do so we have used Monolithic high and low side gate driver IC (FAN7392N). It can drive high-speed MOSFET that operates up to $600 \mathrm{~V}$.

In case the amount of radiation is not sufficient enough to provide the required voltage in order to run the motor we have a backup source as a power grid. 


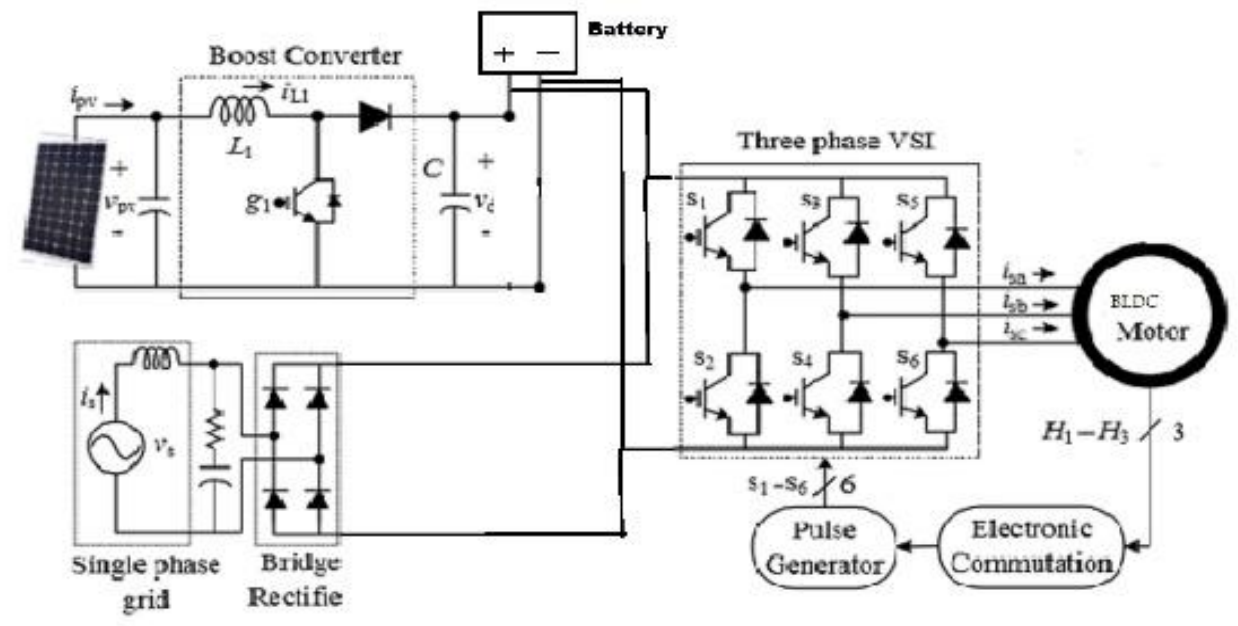

\section{Fig.7 Circuit Diagram}

Whenever PV-Battery system fails to run the motor we switch on to our backup source single phase grid supply. The single phase AC supply i.e. $230 \mathrm{~V}$ is being stepped down to $12 \mathrm{~V}$ by the step-down transformer. This $12 \mathrm{~V}$ of Ac supply is now converted into Dc voltage using Bridge rectifier. Now, this $12 \mathrm{~V} \mathrm{dc}$ supply used to run the motor after passing it through VSI, which converts Dc voltage to Ac which is now being used to run the BLDC motor.

\section{SIMULATION OF THE PROPOSED MODEL}

Fig 4.1 shows the Mat lab simulation circuit using which various observation and graphs have been studied, through which we can analyze whether or not the proposed system is effective and efficient for rural areas or not.

\section{Dowerdace,}

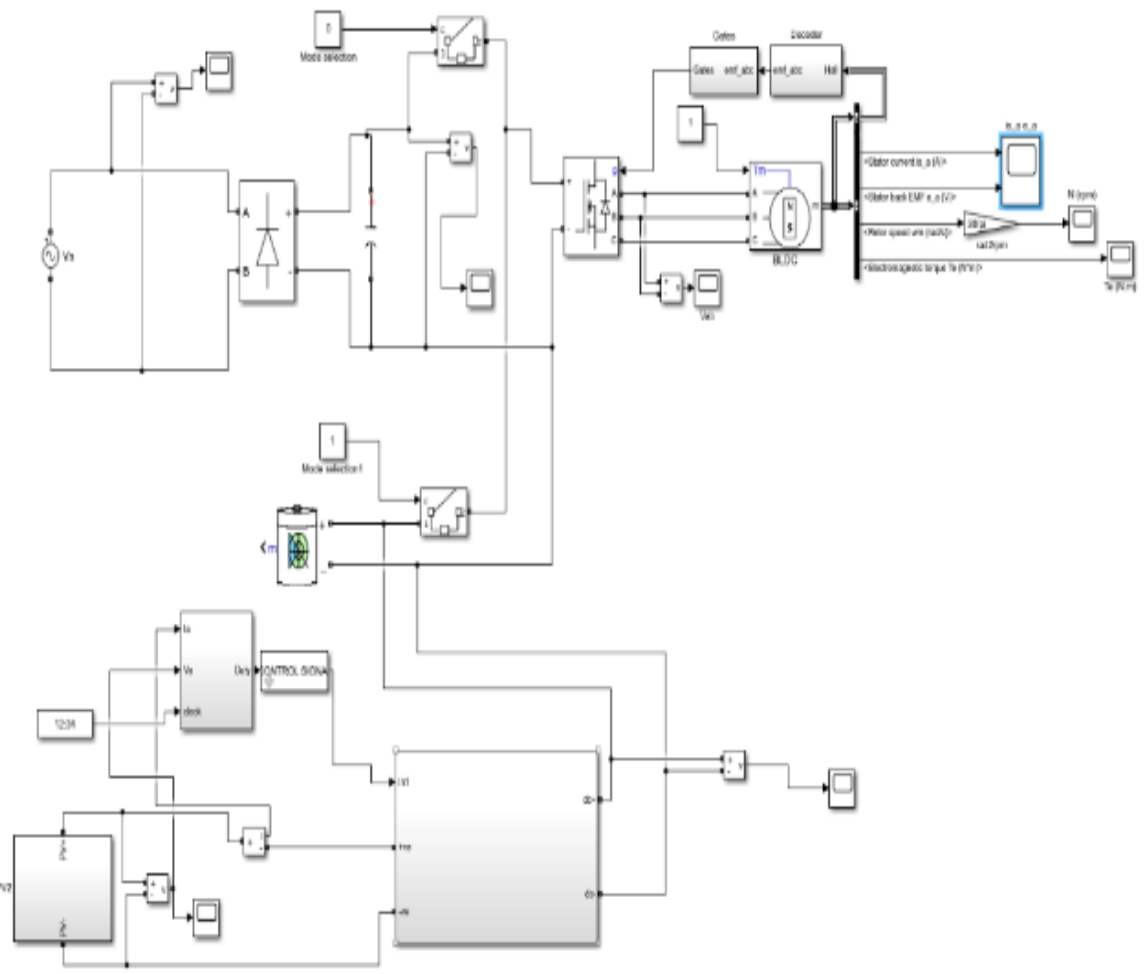

Fig.8 Simulation circuit

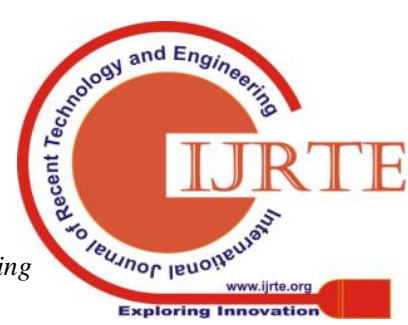




\section{SIMULATION RESULTS}

Single phase grid voltage graph

The input voltage is taken from the grid when solar PV array incapable of running the motor on its own. The voltage is of $400 \mathrm{~V}$ which is given to rectifier so as to change the AC voltage into constant DC voltage.

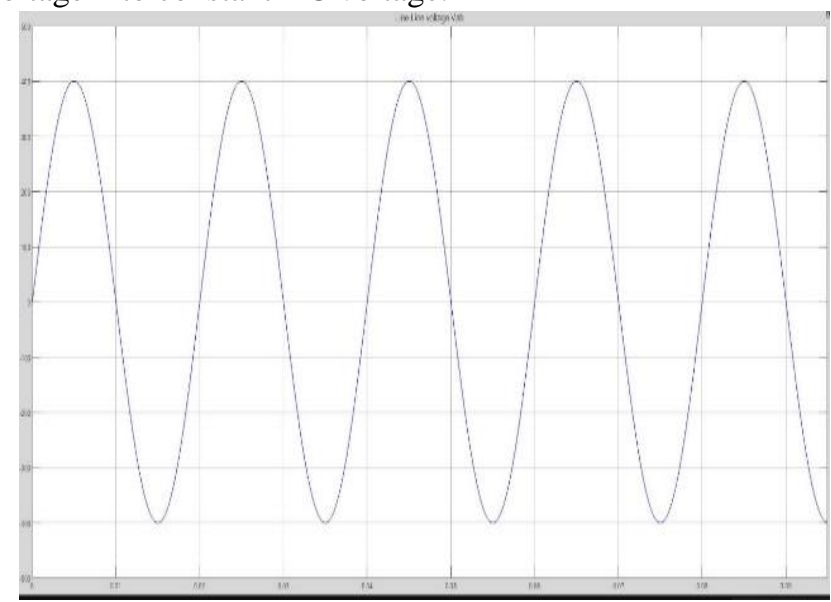

Fig.9 Single Phase Grid Input Voltage

After rectifying voltage graph

The $400 \mathrm{~V}$ AC supply is being fed into the rectifier to convert it into constant DC supply which is used as the input source for the VSI converter. After rectifying the AC voltage the output constant voltage is of $400 \mathrm{~V}(\mathrm{DC})$ as shown in Fig 4.3

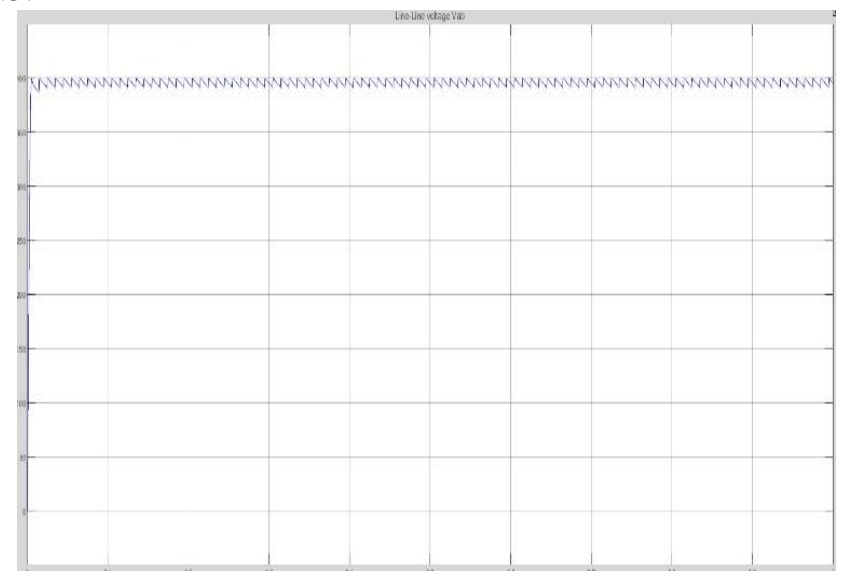

Fig.10 Voltage After Rectifying

\section{PV Panel Voltage}

During the day time when there is a sufficient amount of radiation the voltage we get is of $200 \mathrm{~V}$ which in the ideal case is in DC. As the radiation is kept constant the output of the PV panel will be constant.

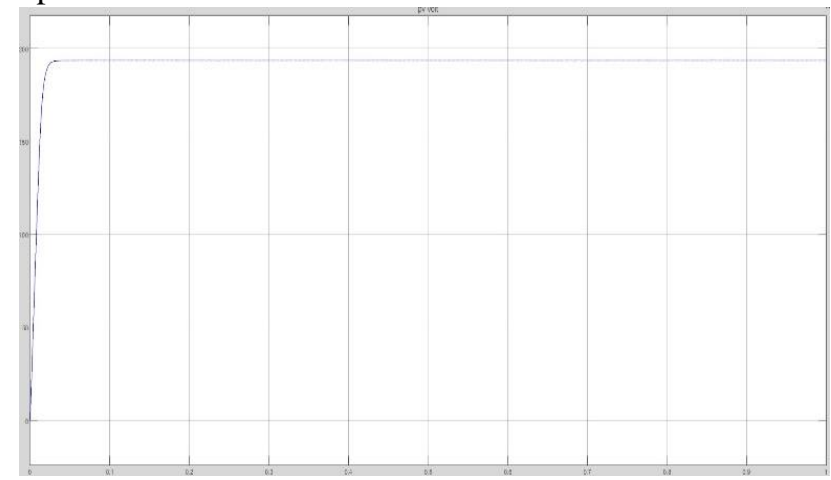

Fig.11 PV Panel Voltage

\section{Voltage After Boosting The PV Panel Voltage}

As the input for the VSI converter is around $400 \mathrm{~V}$ we have boosted the voltage from the solar PV panel to $400 \mathrm{~V}$ using boost converter. The duty cycle for boost converter is $50 \%$ so the output from boost converter is $400 \mathrm{~V}$.

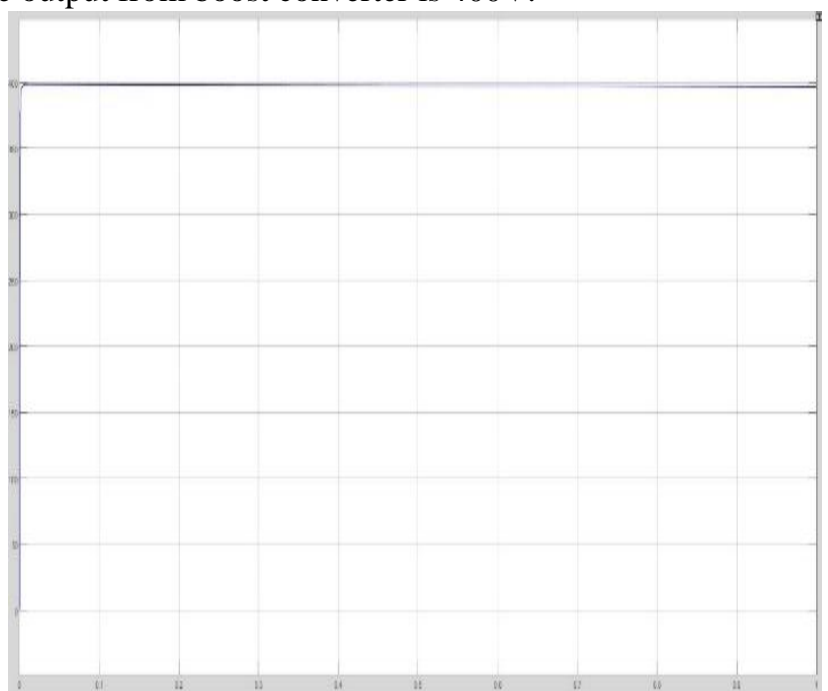

Fig.12 Output Voltage of Boost Converter

Rotor speed graph

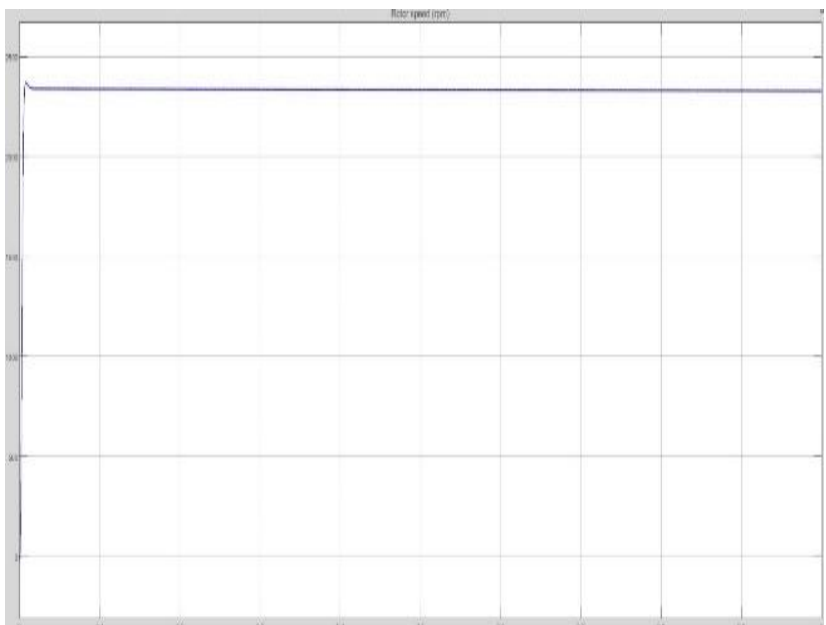

Fig.13 Speed of The Rotor

\section{HARDWARE IMPLEMENTATION}

\begin{tabular}{|c|c|}
\hline Components & Quantity \\
\hline $\begin{array}{l}\text { Step Down } \\
(220-12 \mathrm{~V})\end{array}$ & 2 \\
\hline Capacitor & $\begin{array}{l}2(100 \mu \mathrm{F}), \quad 4(470 \mu \mathrm{F}), \\
1(1000 \mu \mathrm{F})\end{array}$ \\
\hline Inductor & $1(100 \mu \mathrm{H})$ \\
\hline Resistors & $\begin{array}{ll}8(100 \Omega), & 3(1000 \Omega), \\
5(10000 \Omega) & \end{array}$ \\
\hline Mosfet (P4NK60FP) & 6 \\
\hline Microcontroller (PIC16F87) & 1 \\
\hline Diodes (IN4007) & 8 \\
\hline Gate Driver IC (FAN7392) & 3 \\
\hline BLDC motor $(1400 \mathrm{kV})$ & 1 \\
\hline PWM controller (KA3525A) & 1 \\
\hline
\end{tabular}




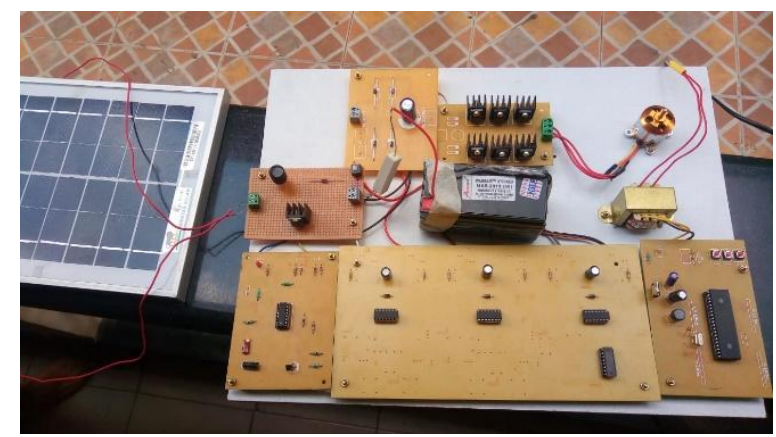

Fig.14 Hardware Setup

\section{CONCLUSION}

Looking at the current energy crisis, renewable energy resources plays an important role to fill the gap between generation and consumption of power. Solar Energy has emerged as one promising source of energy. It is predominant among the renewable energy resources. It can be used for irrigation purposes, driving water pumps in rural areas. Many papers have reported on this topic and is currently under active area of research. A BLDC motor drive fed water pump powered by solar energy is a solution to the energy crisis. The unreliability of PV power due to the weather conditions is resolved by using the power grid as a backup. The proposed system helps the consumer in rural areas to get continuous and reliable motor output required for irrigation irrespective of the weather conditions.

\section{REFERENCES}

1 Investigation and Analysis on the Combined Operation of Solar Thermal Power and Conventional Thermal Power D. Y. Liu, J. Wang, X. Q. Feng, S. Guo, C. Xu

2 Application of Solar Powered Automatic Water Pumping in Turkey. Mahir DURSUN and Semih OZDEN.International Journal of Computer and Electrical Engineering, Vol.4, No.2, April 2012

3 Study of Boost type DC-DC Converter for Single Solar Cell.Atsushi Nakajima,Shigeo Masukawa Department of Electrical and Electronic Engineering, Tokyo Denki University

4 A photovoltaic panel emulator using a buck-boost DC/DC converter and a low cost micro-controller. Dylan D.C. Lu , Quang Ngoc Nguyen chool of Electrical and Information Engineering, The University of Sydney, NSW 2006, Australia

5 Buck-Boost Converter Fed BLDC Motor Drive for Solar PV Array Based Water Pumping. Drive Rajan Kumarl and Bhim Singh2 IMember, IEEE, 2 Fellow, IEEE 1, 2Department of Electrical Engineering, Indian Institute of Technology Delhi, Hauz Khas, New Delhi-1100 16, India

6 Huang, "Photovoltaic Water Pumping and Residual Electricity Grid Connected System," Chinese Patent CN 204131142 U, Jan. 28, 2015.

7 Design, Simulation and Implementation of a Grid Tied Solar Power Controller Integrated with Instant Power Supply Technology.Masum Billah, Sanjoy Kumar Das, Md. Toriqul Islam, Md. Anamul Haque, Bishwajit Banik Pathik. Dept. of Electrical and Electronic Engineering American International University-Bangladesh (AIUB), Dhaka, Bangladesh

8 P. K. Singh, B. Singh and V. Bist, "Brushless DC motor drive with power factor regulation using Landsman converter," IET Power Electron., vol. 9, no. 5, pp. 900-910, Apr. 2016.
9 C. L. Xia, Permanent Magnet Brushless DC Motor Drives and Controls. Beijing, China: Wiley, 2012.

10 Implementation of a Three Phase Inverter forBLDC Motor Drive Adnan Mohammad, Md. Anwarul Abedin, and Md. Ziaur Rahman Khan Department of Electrical and Electronic Engineering,Bangladesh University of Engineering and Technology (BUET) Dhaka University of Engineering and Technology (DUET) Dhaka, Bangladesh

11 Solar PV-Battery based Hybrid Water Pumping System using BLDC Motor Drive Rajan Kumarl and Bhim Singh2 IMember, IEEE, 2 Fellow, IEEE 1, 2Department of Electrical Engineering, Indian Institute of Technology Delhi, Hauz Khas, New Delhi-1100 16, India

12 PV Power System Based MPPT Z-Source Inverter to Supply a Sensorless BLDC Motor.S.A.KH. Mozafari Niapoor, Student Member IEEE , S. Danyali, M.B.B. Sharifian Faculty of Electrical \& Computer Engineering, University of Tabriz, Tabriz, Iran.1st Power Electronic \& Drive Systems \& Technologies Conference

13 Rajan Kumar and Bhim Singh, "BLDC motor-driven water pump fed by solar photovoltaic array using boost converter," Annu. IEEE India Conf. (INDICON), New Delhi, 2015. 